\title{
Sistema de produção de alface em ambiente parcialmente modificado por túneis baixos
}

\author{
A system to grow lettuce inside low plastic tunnels
}

\author{
Luciano Streck ${ }^{\mathrm{I}}$ Flavio Miguel Schneider ${ }^{\mathrm{II}}$ Galileo Adeli Buriol ${ }^{\mathrm{III}}$ \\ Jovani Luzza ${ }^{\text {IV }}$ Miguel Ângelo Sandri ${ }^{\mathrm{IV}}$
}

\section{RESUMO}

O objetivo no trabalho foi obter um sistema para a produção de alface em túneis baixos, ao longo de todo o ano, e que minimize o manejo de ventilação. Para isso, foram realizados 13 cultivos de alface no período de outubro de 1994 a julho de 1997. Os tratamentos de inverno constaram dos seguintes tipos de coberturas: a) Cultivo em túnel convencional com cobertura de polietileno de baixa densidade e com manejo conforme as condições meteorológicas; b)cultivo em túnel plástico com $3 \%$ de área perfurada, sem manejo diário de ventilação; c) cultivo em túnel plástico tipo guardachuva com as laterais abertas na base o ano inteiro, sem manejo diário de ventilação; d) cultivo testemunha sem cobertura durante todo o ano. Os tratamentos de verão constaram dos anteriormente citados, sendo as coberturas, dos tratamentos com túneis convencionais e perfurados substituídas por tela plástica preta de $30 \%$ de sombreamento. Os resultados obtidos permitem indicar como sistema para produção de alface ao longo de todo o ano a utilização de túneis cobertos com polietileno transparente em forma de guarda-chuva. Recomenda-se esta técnica, sendo necessário apenas o ajuste da altura das aberturas laterais de acordo com a época do ano.

Palavras-chave: hortaliças folhosas, túnel convencional, túnel guarda-chuva, túnel perfurado, túnel tela plástica, ventilação.

\section{ABSTRACT}

Four different covers were tested to obtain a system to produce vegetables throughout the year under low tunnels without ventilation management. Lettuce, cv. Regina, was grown during thirteen plantings from October 1994 to July 1997. The winter treatments were: a) low tunnel with transparent polyethylene without perforations and with conventional management according to the meteorological conditions; b) low tunnel with 3\% perforated transparent polyethylene and without ventilation management; c) umbrella-like, low tunnel with transparent polyethylene with open laterals throughout the year and without ventilation management; d) cropping without tunnel throughout the year, as a control. The treatments in the summer were similar to the winter treatments with conventional and perforated covers replaced by a black plastic screen with a $30 \%$ reduction in solar radiation. Results indicated that the umbrella-like tunnels can be used instead of conventional low tunnels, which need daily management. This technique allows lettuce to grow throughout the year and only requires the laterals adjustment, according to the year season.

Key words: vegetables, conventional tunnel, umbrella tunnel, perforated tunnel, plastic screen tunnel, ventilation.

\section{INTRODUÇÃO}

Originária da Ásia, a alface é uma das saladas folhosas mais presente na mesa dos brasileiros, principalmente devido à adaptação das suas cultivares, que permite o seu cultivo ao longo de todo o ano (FILGUEIRA, 2000). Devido a sua origem, as cultivares de alface crescem e se desenvolvem bem em temperaturas amenas, tendo como fatores limitantes os danos causados às folhas pelos ventos frios e pelas geadas. Já no verão, os fatores limitantes são as chuvas

'Universidade Estadual do Rio Grande do Sul (UERGS), Rua Marechal Floriano Peixoto, 4557, Bairro Agrícola, 97800-000, São Luiz Gonzaga, RS, Brasil. E-mail: streckl@gmail.com. Autor para correspondência.

IIDepartamento de Fitotecnia, Centro de Ciências Rurais (CCR), Universidade Federal de Santa Maria (UFSM), Santa Maria, RS, Brasil. In memorian.

IIIEngenharia Ambiental, Centro Universitário Franciscano (UNIFRA), Santa Maria, RS, Brasil.

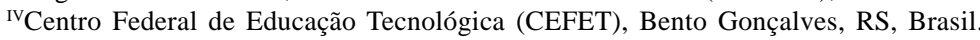


convectivas, de curta duração e de alta intensidade, a elevada densidade de fluxo de radiação solar incidente e as altas temperaturas do ar, que favorecem o apendoamento das plantas e o acúmulo de látex nas folhas (FILGUEIRA, 2000).

Para minimizar esses problemas, tem-se recomendado o uso da técnica de cultivo da alface em túneis plásticos baixos. Além de suas estruturas serem de porte menor em relação às estufas e aos túneis altos, são de menor custo e de fácil construção, possibilitam a proteção das plantas às chuvas e aos ventos e ainda proporcionam ambiente com maior soma térmica diurna, imprescindível na estação fria (ROBLEDO \& MARTIN, 1981). O uso da técnica resulta em ganho na precocidade e na qualidade de produção da cultura da alface. Entretanto, o sucesso dessa técnica está condicionado ao manejo correto da ventilação dos túneis (abertura e fechamento), prática diária que depende de mão-de-obra e tempo. Como alternativa, BURIOL et al. (1997) testaram a utilização de horários fixos para a realização da abertura e do fechamento dos túneis plásticos e constataram que a ventilação dos túneis não foi suficientemente adequada para a produção de alface. Segundo LUFT (1994), o manejo de ventilação deve ser realizado de acordo com as condições meteorológicas do dia e, portanto, não tem um horário fixo para a abertura e o fechamento dos túneis.

Com o intuito de facilitar e reduzir a mão-deobra no manejo diário, BURIOL et al. (1993) constataram que o uso de polietileno transparente de baixa densidade, com perfurações, proporcionou condições satisfatórias de ventilação dos túneis baixos. STRECK et al. (1994), em trabalho similar, verificaram que 100 e 300 perfurações de $0,01 \mathrm{~m}$ de diâmetro por $\mathrm{m}^{2}$ foram adequadas para cultivos de alface no inverno e na primavera, respectivamente. Esta adaptação prescinde do manejo diário de ventilação, sendo necessária apenas a adequação da área perfurada à época de cultivo. Na estação quente, GIMENES et al. (1994) recomendam o uso de malhas comerciais (sombrite) com 30\% de atenuação da densidade de fluxo de radiação solar incidente. A utilização das mesmas possibilita que ocorram condições favoráveis ao crescimento das plantas de alface na região de Santa Maria (BURIOL et al., 1994).

A partir da utilização de túneis com coberturas plásticas adequadas à época do ano, é possível a inferência de que o manejo de ventilação pode ser minimizado, segundo os resultados obtidos por BURIOL et al. (1993, 1994), STRECK et al. (1994) e GIMENES et al. (1994), ao longo de todo ano, sem prejudicar a produção de alface de boa qualidade.
Assim, além de contribuir com a manutenção da regularidade na oferta exigida pelo mercado, ainda podem ser diminuídos os seus custos de produção. Dessa forma, o objetivo do trabalho foi obter um sistema para produção de alface em túneis baixos, que minimize o manejo de ventilação e que possibilite a produção de alface de qualidade ao longo de todo o ano.

\section{MATERIAL E MÉTODOS}

O experimento foi conduzido no Departamento de Fitotecnia da Universidade Federal de Santa Maria, RS (latitude: 29 41'S, longitude: 5348' $\mathrm{W}$ e altitude: $95 \mathrm{~m}$ ), no período de outubro de 1994 a julho de 1997. O solo do local pertence à unidade de mapeamento São Pedro e é classificado como ARGISSOLO VERMELHO Distrófico arênico (EMBRAPA, 1999).

A cultivar de alface utilizada foi a "Regina”, do grupo de folhas lisas, realizando-se 13 cultivos sucessivos na mesma área ao longo do período. Os canteiros foram orientados no sentido norte-sul, tendo as dimensões de $1,0 \mathrm{~m}$ de largura e $25,0 \mathrm{~m}$ de comprimento. No preparo dos canteiros, foi realizada adubação química de manutenção com $80 \mathrm{~kg} \mathrm{ha}^{-1}$ de N, $140 \mathrm{~kg} \mathrm{ha}^{-1}$ de $\mathrm{P}_{2} \mathrm{O}_{5}$ e $120 \mathrm{~kg} \mathrm{ha}^{-1}$ de $\mathrm{K}_{2} \mathrm{O}$, a qual foi incorporada ao solo com auxílio de enxada rotativa, aproximadamente dois dias antes do transplante.

A produção das mudas foi feita em bandejas de isopor com substrato, sendo as plantas transplantadas com três a cinco folhas definitivas. $\mathrm{O}$ espaçamento utilizado foi de $0,20 \mathrm{~m}$ entre fileiras e de $0,30 \mathrm{~m}$ entre plantas na fileira. Após o transplante, foram construídos túneis baixos sustentados por arcos de ferro e cobertos com filme de polietileno de baixa densidade ou com tela plástica, dependendo da época do ano. Os túneis tiveram as dimensões de comprimento e largura idênticas às dos canteiros e a altura de $0,5 \mathrm{~m}$ na parte central do canteiro. A irrigação foi feita por duas linhas de tubos gotejadores colocados entre as fileiras laterais e as centrais na extensão de cada canteiro.

Os cultivos de inverno foram até o início da primavera e os cultivos de verão foram até o início do outono, sendo feita a transição entre as épocas do ano, com a troca de tipos de cobertura, somente após o término do cultivo. Os tratamentos de inverno constaram dos seguintes tipos de coberturas/manejo de ventilação: a) Cultivo em túnel convencional (Cvnl), com cobertura de polietileno de baixa densidade, não perfurado e com manejo de ventilação conforme as 
condições meteorológicas do dia; b) cultivo em túnel perfurado (Perf), com polietileno de baixa densidade com perfurações de 0,01m de diâmetro em 3\% de área de cobertura e uniformemente distribuídas na cobertura, sem manejo diário de ventilação; c) cultivo em túnel tipo guarda-chuva $(G C)$, com polietileno de baixa densidade, tendo as laterais abertas na base o ano inteiro e sem manejo diário de ventilação; d) cultivo em ambiente natural, sem cobertura durante todo o ano (Test). Os tratamentos de verão constaram dos tratamentos anteriormente descritos, sendo as coberturas dos tratamentos com túneis plásticos convencional e perfurado substituídas por tela plástica preta (sombrite) de 30\% de sombreamento (Tela), conforme a recomendação para a cultura na região (BURIOL et al., 1994). Os túneis tipo guarda-chuva foram conduzidos com as duas laterais abertas em $0,05 \mathrm{~m}$ no período de inverno e $0,10 \mathrm{~m}$ no período de verão. Os mesmos foram construídos a partir de filmes plásticos de $2,20 \mathrm{~m}$ de largura, divididos ao meio longitudinalmente. As extremidades dos arcos foram enterradas no solo até que se obtivessem aberturas laterais com a altura adequada à época do ano.

Foram utilizadas três repetições por tratamento por época de cultivo, sendo que cada canteiro constituiu uma parcela de tratamento. As avaliações foram realizadas com base nas determinações da massa da matéria fresca e do número de folhas por planta. Para isso, foram coletadas quatro plantas em quatro pontos do canteiro, nas duas fileiras centrais, totalizando 16 plantas por coleta por repetição. As coletas foram realizadas a intervalos de sete dias, entre $8 \mathrm{~h}$ e $10 \mathrm{~h}$ da manhã, visando a obterem-se plantas com mesma hidratação potencial. Na contagem do número de folhas, foram consideradas aquelas com no mínimo 0,02m de comprimento. O término dos cultivos foi quando as plantas se apresentavam no "ponto de colheita” para a comercialização, com cerca de 40 folhas. Os seus valores médios, do número de folhas e da massa da matéria fresca, foram avaliados por comparação de médias por teste de Duncan em nível de $5 \%$ de probabilidade de erro.

Para a caracterização das modificações ambientais sob os diferentes tratamentos, foram instalados termógrafos em uma repetição de cada tratamento. No período de inverno, foi determinada a variação da temperatura do ar no período das $07 \mathrm{~h}$ as 19h do dia 11/06/1996 e a média bi-horária no intervalo de dias de 20/05 a 20/07 de 1997. Para o período de verão, as temperaturas médias bi-horárias e as máximas do ar foram obtidas a partir dos registros ao longo do período de 03/02 a 26/02 de 1997.

\section{RESULTADOS E DISCUSSÃO}

No decorrer dos cultivos de inverno, verificou-se ganho distinto entre as plantas sob os tratamentos com túneis plásticos, se comparadas às plantas do tratamento testemunha, tanto com relação à massa da matéria fresca quanto ao número de folhas (Figura 1). Esse efeito positivo pode ser notado desde o início das coletas até o ponto de colheita das plantas e confirma os benefícios da utilização dos túneis plásticos no cultivo de hortaliças folhosas (ROBLEDO \& MARTIN, 1981). As maiores diferenças no crescimento das plantas, em função dos dias após o transplante (DAT) e nos diferentes tratamentos, principalmente com relação à massa da matéria fresca, ocorreram na 3aㅗ 5a e 7a épocas de cultivo (Figura 1). Esses cultivos foram realizados nos períodos mais frios dos anos de 1995, 1996 e 1997 e alcançaram 54, 60 e 63 DAT, respectivamente.

A partir da análise estatística e com base na variável massa fresca (Tabela 1), observada no ponto de colheita das plantas de alface, verificou-se que os tratamentos túneis plásticos convencional (Cvnl), guarda-chuva (GC) e perfurado (Perf) foram equivalentes entre si e, em apenas três cultivos, superiores à testemunha (Test). Apesar de os valores médios de massa fresca não apresentarem diferença estatística (Tabela 1), observou-se que o tratamento com túnel GC está por seis vezes entre os dois primeiros tratamentos com maior massa fresca, enquanto o tratamento com túnel Perf somente duas vezes e o tratamento com túnel Cvnl cinco vezes entre os dois primeiros. A partir disso, infere-se que ocorre maior similaridade entre os tratamentos com túneis Cvnl e GC.

Quanto ao número de folhas por planta, no ponto de colheita, houve maior variabilidade em função dos tratamentos e épocas de cultivo e as diferenças foram significativas entre os tratamentos (Tabela 1). No entanto, a produção de alface, com aspecto visual apreciável, prescinde de plantas com número elevado de folhas, em preferência a folhas com tamanho aprazível. Dessa forma, a massa média de 6,70g, 6,67g, $6,16 \mathrm{~g}$ e $5,30 \mathrm{~g}$ por folha das plantas dos tratamentos túneis Cvnl, GC, Perfe Test, respectivamente, servem de indicativo indireto do tamanho das folhas. Esses valores expõem que existe similaridade entre os tratamentos túneis Cvnl e GC e destes com o tratamento túnel Perf.

A partir dos resultados, pode-se confirmar que a técnica dos túneis Cvnl é eficiente na produção de alface, sendo recomendada principalmente para as 


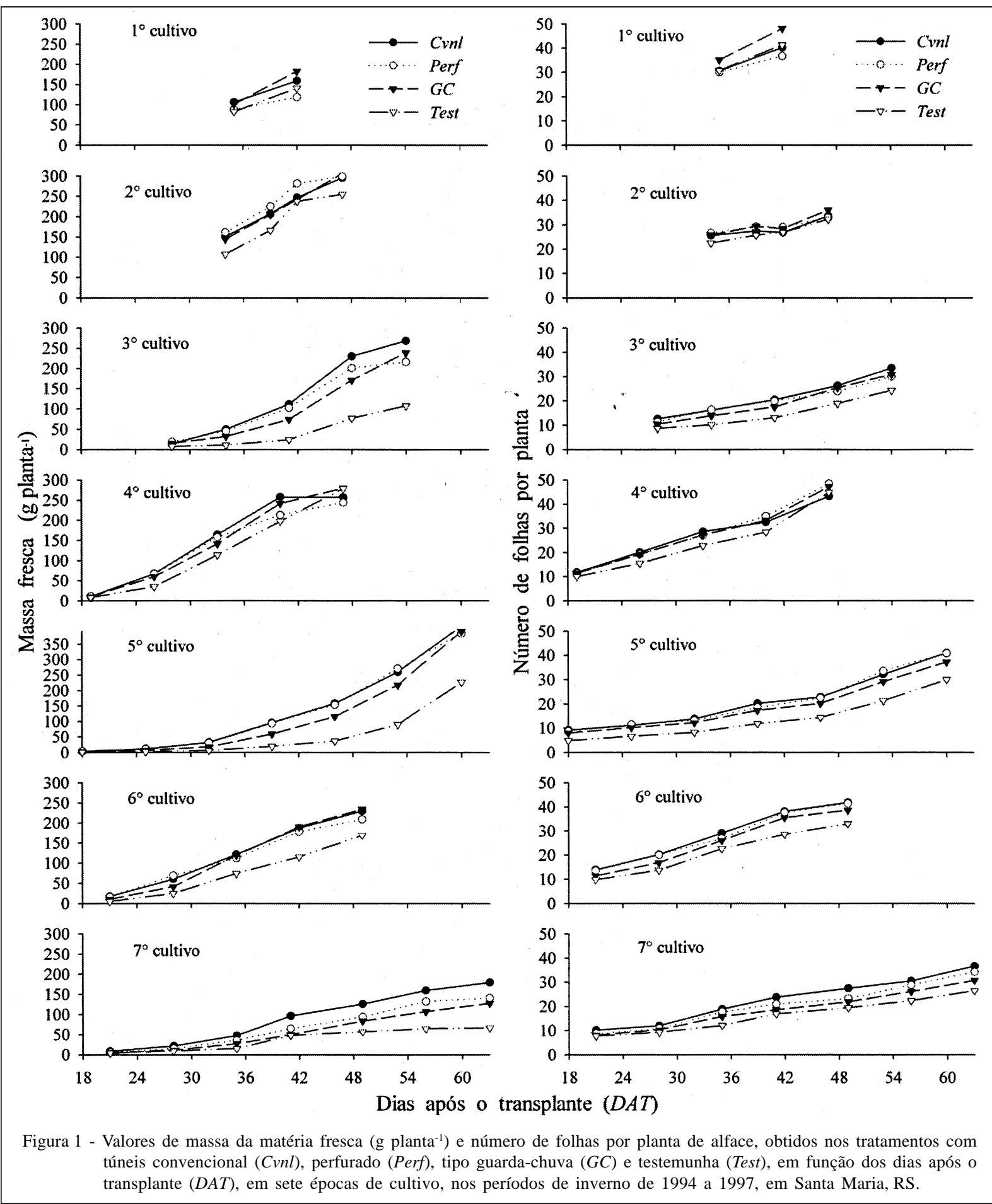

propriedades com mão-de-obra disponível para a realização do manejo de ventilação diária dos túneis. A importância do manejo dos túneis pode ser observada na figura $2 d$, com a redução significativa da temperatura do ar após a abertura dos túneis Cvnl. Esse comportamento também foi constatado por BURIOL et al. (1997) e vem a reiterar a necessidade do controle rigoroso no manejo de ventilação, prática dispensada nos tratamentos com túneis GC e Perf. As figuras 2c e $2 \mathrm{~d}$ ainda permitem constatar que os valores de temperatura do ar, nos tratamentos com túneis Cvnl, GC e Perf, foram similares entre si e um pouco superiores

Ciência Rural, v.37, n.3, mai-jun, 2007. 
Tabela 1 - Número de dias após a data de transplante (DAT) e data do ponto de colheita da alface nos diferentes cultivos, médias do número de folhas e da massa da matéria fresca (g) por planta, para os tratamentos com cobertura convencional, perfurada, tipo guardachuva e sem cobertura (testemunha), em sete épocas de cultivo, média geral e coeficiente de variação (\%) dos dados dos tratamentos, nos períodos de inverno de 1994 a 1997, em Santa Maria-RS.

\begin{tabular}{|c|c|c|c|c|c|c|c|c|}
\hline Cultivo & Tratamentos & $\begin{array}{l}\text { Média do número de } \\
\text { folhas }\end{array}$ & & & Tratamentos & $\begin{array}{l}\text { Média da massa da } \\
\text { matéria fresca }\end{array}$ & & \\
\hline & Guarda-chuva & $48,125^{*}$ & A & & Guarda-chuva & $182,25^{*}$ & A & \\
\hline 01 & Testemunha & 41,333 & A & B & Convencional & 159,00 & A & \\
\hline 42 DAT & Convencional & 40,208 & & B & Testemunha & 141,08 & A & \\
\hline \multirow[t]{2}{*}{$29 / 11 / 94$} & Perfurado & 36,708 & & B & Perfurado & 118,62 & A & \\
\hline & Guarda-chuva & 36,000 & A & & Guarda-chuva & 305,79 & A & \\
\hline 02 & Convencional & 33,604 & B & & Perfurado & 298,52 & A & \\
\hline $47 D A T$ & Perfurado & 32,938 & B & & Convencional & 295,67 & A & \\
\hline \multirow[t]{2}{*}{ 21/06/95 } & Testemunha & 32,250 & B & & Testemunha & 254,52 & A & \\
\hline & Convencional & 33,497 & A & & Convencional & 268,57 & A & \\
\hline 03 & Guarda-chuva & 30,890 & A & B & Guarda-chuva & 239,25 & A & \\
\hline 54 DAT & Perfurado & 30,045 & & B & Perfurado & 216,40 & A & \\
\hline \multirow[t]{2}{*}{ 05/09/95 } & Testemunha & 24,257 & $\mathrm{C}$ & & Testemunha & 107,68 & B & \\
\hline & Perfurado & 48,438 & A & & Guarda-chuva & 279,52 & A & \\
\hline 04 & Guarda-chuva & 47,229 & A & & Testemunha & 278,44 & A & \\
\hline $47 D A T$ & Testemunha & 44,958 & A & B & Convencional & 257,15 & A & \\
\hline \multirow[t]{2}{*}{ 08/11/95 } & Convencional & 43,292 & & B & Perfurado & 244,08 & A & \\
\hline & Convencional & 41,000 & A & & Convencional & 408,46 & A & \\
\hline 05 & Perfurado & 40,792 & A & & Guarda-chuva & 391,12 & A & \\
\hline $60 \mathrm{DAT}$ & Guarda-chuva & 37,229 & B & & Perfurado & 385,00 & A & \\
\hline \multirow[t]{2}{*}{ 27/08/96 } & Testemunha & 30,021 & $\mathrm{C}$ & & Testemunha & 226,85 & B & \\
\hline & Convencional & 41,833 & A & & Guarda-chuva & 234,27 & A & \\
\hline 06 & Perfurado & 41,438 & A & & Convencional & 230,10 & A & \\
\hline 49 DAT & Guarda-chuva & 38,688 & A & & Perfurado & 208,90 & A & \\
\hline \multirow[t]{2}{*}{ 24/10/96 } & Testemunha & 33,000 & B & & Testemunha & 169,62 & A & \\
\hline & Convencional & 36,667 & A & & Convencional & 179,35 & A & \\
\hline 07 & Perfurado & 34,250 & A & & Perfurado & 140,69 & A & B \\
\hline 63 DAT & Guarda-chuva & 30,708 & B & & Guarda-chuva & 128,02 & & B \\
\hline $15 / 07 / 97$ & Testemunha & 26,458 & $\mathrm{C}$ & & Testemunha & 66,73 & $\mathrm{C}$ & \\
\hline \multirow{4}{*}{$\begin{array}{l}\text { Média geral dos } \\
\text { tratamentos }\end{array}$} & Convencional & 39,39 & & & Convencional & 263,73 & & \\
\hline & Perfurado & 39,24 & & & Perfurado & 259,74 & & \\
\hline & Guarda-chuva & 38,80 & & & Guarda-chuva & 242,80 & & \\
\hline & Testemunha & 33,95 & & & Testemunha & 192,98 & & \\
\hline \multirow{4}{*}{$\begin{array}{l}\text { Coeficiente de } \\
\text { variação (CV \%) }\end{array}$} & Convencional & 18,12 & & & Convencional & 40,38 & & \\
\hline & Perfurado & 20,41 & & & Perfurado & 47,58 & & \\
\hline & Guarda-chuva & 21,99 & & & Guarda-chuva & 46,31 & & \\
\hline & Testemunha & 24,61 & & & Testemunha & 49,15 & & \\
\hline
\end{tabular}

*Médias não seguidas pela mesma letra diferem estatisticamente entre si pelo teste de Duncan em nível de 5 \% de probabilidade de erro. 


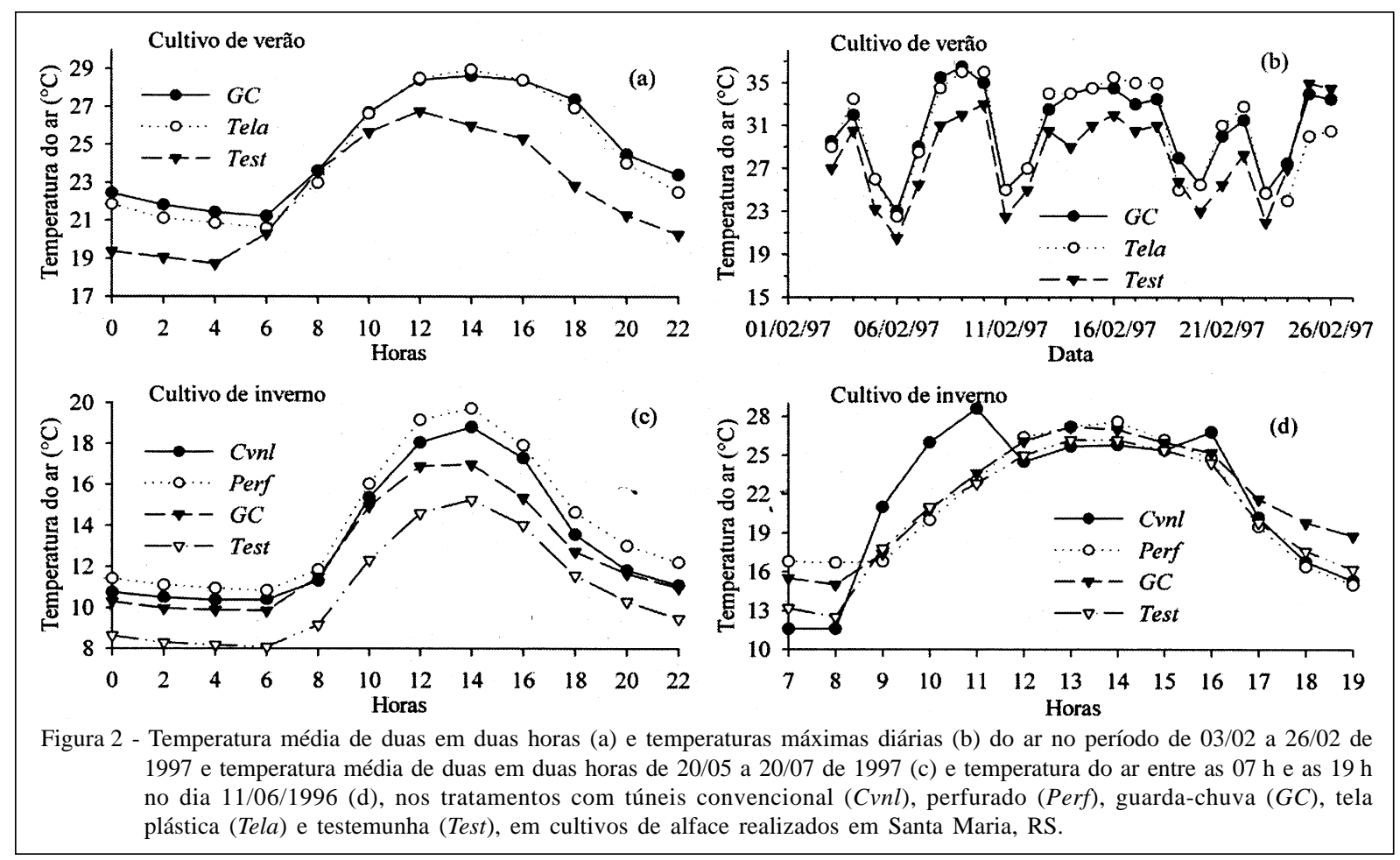

ao tratamento Test e estiveram situados na faixa favorável para o cultivo da alface (CERMEÑO, 1988).

Os resultados obtidos permitem afirmar que os cultivos de alface no inverno podem ser realizados sob túneis GC e Perf, em substituição aos túneis Cvnl. O tratamento com túneis $G C$, sem a necessidade de abertura e fechamento das laterais, no qual a ventilação ocorre apenas pelas aberturas laterais permanentes de 0,05m, durante o período de inverno, produziu plantas com massa fresca e qualidade satisfatórias. Essas aberturas laterais têm efeito equivalente ao proporcionado pelo número de perfurações do tratamento com túneis Perf. No caso dos túneis $G C$, o filme plástico sofre menor atrito com os arcos de sustentação, se comparados aos túneis Cvnl, devido à inexistência do manejo diário de ventilação. Ainda podese aventar que a resistência do filme plástico à atuação dos ventos seja maior do que a dos túneis Perf, pela ausência dos furos para ventilação, prolongando a durabilidade do filme plástico.

Nos cultivos no período de verão (outubro a março), a partir dos valores médios de ganho de massa fresca e de número de folhas, apresentados na figura 3, pode-se observar que o crescimento das plantas de alface ocorreu de modo diferenciado e foi favorecido no interior dos túneis $G C$, enquanto que os valores médios de ganho de massa fresca e de número de folhas dos tratamentos com túneis Tela foram muito similares aos do tratamento Test (Figura 3).
A partir da análise estatística dos valores da variável massa fresca, no ponto de colheita das plantas, foi observado que, somente na terceira época de cultivo, o tratamento com túneis GC foi superior ao tratamento com túneis Tela (Tabela 2). Para as demais épocas de cultivo, a média da massa fresca não diferiu significativamente entre os tratamentos com túneis $G C$ e Tela pelo teste de Duncan (Tabela 2). O número de folhas no tratamento com túneis $G C$ foi estatisticamente superior ao tratamento com túneis Tela em todos os cultivos e ao tratamento Test em três cultivos. Os túneis com cobertura de tela plástica de 30\% de atenuação da radiação solar proporcionaram plantas com o menor número de folhas em todos os cultivos realizados. Entretanto, o seu valor de massa fresca média foi de $4,70 \mathrm{~g}$ folha $^{-1}$, similar ao tratamento com túneis GC com 4,69 folha $^{-1}$, sendo ambos superiores ao tratamento Test, que apresentou valor médio de 4,18g folha ${ }^{-1}$.

A utilização dos túneis Tela proporcionou a obtenção de plantas com folhas tenras e suculentas, que é característica desejada nos cultivos de hortaliças folhosas. Estas características decorrem da menor disponibilidade de radiação solar associada à temperatura do ar elevada nos tratamentos com túneis Tela (Figura 2a e 2b), resultando em plantas com maior estiolamento. Entretanto, por ocasião da realização das coletas, observaram-se folhas quebradiças. Essa observação prática não foi mensurada, no entanto, é importante seu relato, pois esse aspecto passa a ser

Ciência Rural, v.37, n.3, mai-jun, 2007. 


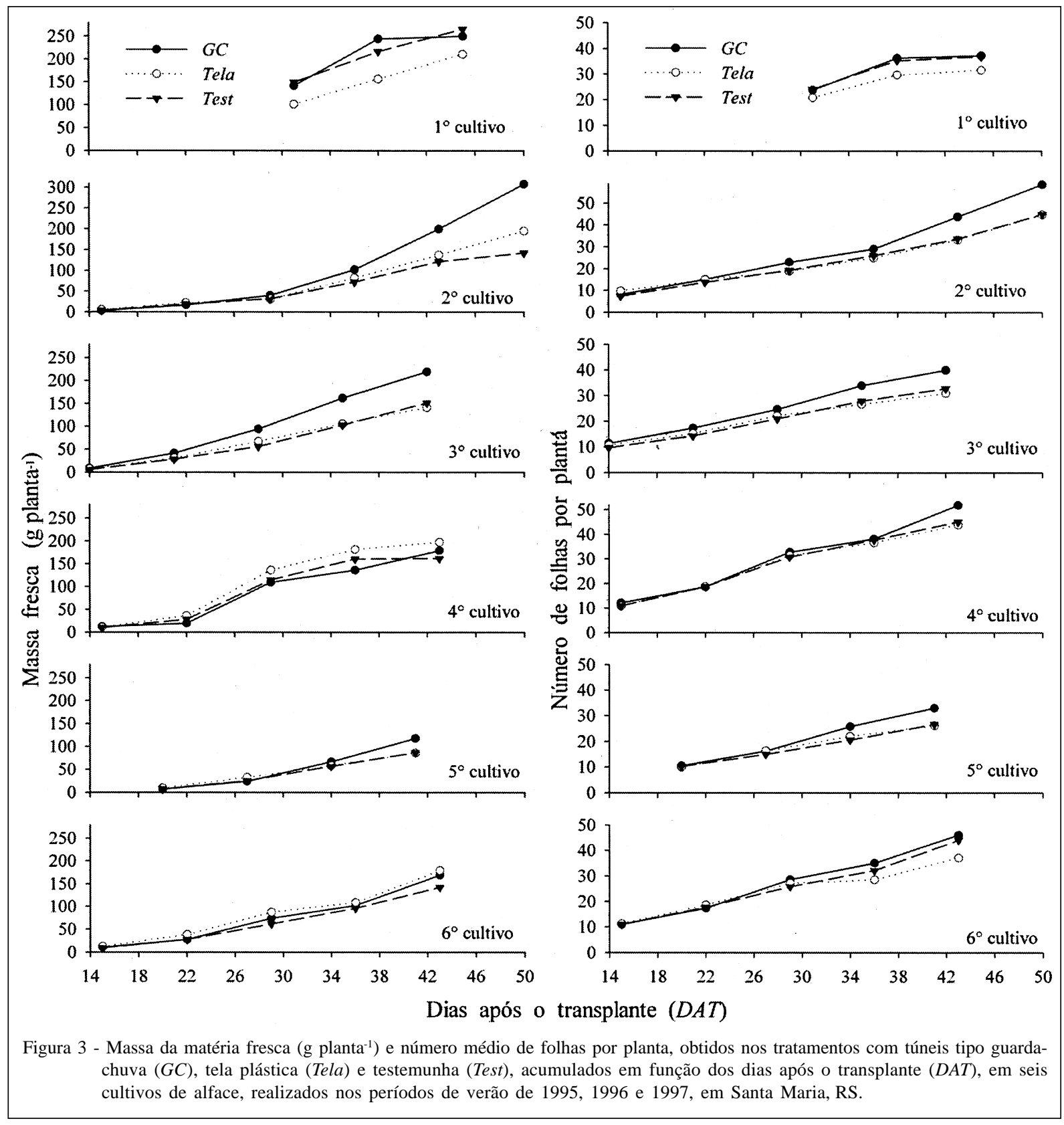

um problema quando é necessário se realizar o manuseio do produto e o transporte a médias e longas distâncias. As folhas frágeis podem ser facilmente danificadas, diminuindo a qualidade da alface.

Observou-se que os valores médios da temperatura bi-horária do ar nos tratamentos com túneis GC e Tela foram similares entre si e superiores aos do tratamento Test (Figura 2a). Assim não foi confirmada a expectativa de que os valores de temperatura do ar fossem mais amenos sob o tratamento com túneis Tela. No entanto, as temperaturas máximas do ar foram superiores a $30^{\circ} \mathrm{C}$, ou seja, superiores à faixa de temperatura satisfatória para o cultivo da alface, nos três tratamentos. Esse fato corrobora a hipótese de que os níveis térmicos devem ter influenciado negativamente no crescimento e na qualidade da alface produzida (Figura $2 b$ ).

A observação dos resultados dos cultivos de verão, permite inferir que a utilização dos túneis Tela tem potencialidade para ser recomendada no período mais quente do ano. No entanto, para as latitudes em que ocorre redução da disponibilidade de energia solar nas épocas de final de verão e de início de outono, não se recomenda o uso da tela plástica, 
Tabela 2 - Número de dias após o transplante (DAT) e data do ponto de colheita da alface, médias do número de folhas e da massa da matéria fresca (g) por planta, para os tratamentos com túneis tipo guarda-chuva, tela plástica e sem cobertura (testemunha) em seis cultivos de alface, média geral e coeficiente de variação (\%) dos dados dos tratamentos, nos períodos de verão de 1995 a 1997, em Santa Maria-RS.

\begin{tabular}{|c|c|c|c|c|c|c|c|c|}
\hline Cultivo & Tratamentos & $\begin{array}{l}\text { Média do número de } \\
\text { folhas }\end{array}$ & & & Tratamentos & $\begin{array}{l}\text { Média da massa da } \\
\text { matéria fresca }\end{array}$ & & \\
\hline 01 & Guarda-chuva & $37,269 *$ & $\mathrm{~A}$ & & Testemunha & $265,37 *$ & $\mathrm{~A}$ & \\
\hline $45 D A T$ & Testemunha & 36,833 & A & B & Guarda-chuva & 249,79 & A & \\
\hline 24/04/95 & Tela plástica & 31,542 & & B & Tela plástica & 210,90 & A & \\
\hline 02 & Guarda-chuva & 58,625 & A & & Guarda-chuva & 308,02 & A & \\
\hline $50 D A T$ & Testemunha & 44,854 & B & & Tela plástica & 194,83 & A & B \\
\hline $23 / 02 / 96$ & Tela plástica & 44,729 & B & & Testemunha & 142,50 & & B \\
\hline 03 & Guarda-chuva & 39,958 & A & & Guarda-chuva & 219,31 & A & \\
\hline $42 D A T$ & Testemunha & 32,729 & B & & Testemunha & 151,25 & B & \\
\hline $24 / 04 / 96$ & Tela plástica & 30,958 & B & & Tela plástica & 141,37 & B & \\
\hline 04 & Guarda-chuva & 51,750 & A & & Tela plástica & 197,62 & A & \\
\hline $43 D A T$ & Testemunha & 45,104 & B & & Guarda-chuva & 179,15 & A & \\
\hline $21 / 12 / 96$ & Tela plástica & 43,917 & B & & Testemunha & 161,81 & A & \\
\hline 05 & Guarda-chuva & 32,979 & A & & Guarda-chuva & 117,81 & A & \\
\hline $41 D A T$ & Testemunha & 26,667 & A & B & Testemunha & 86,90 & A & \\
\hline $21 / 02 / 97$ & Tela plástica & 26,125 & & B & Tela plástica & 86,27 & A & \\
\hline 06 & Guarda-chuva & 46,021 & A & & Tela plástica & 179,00 & A & \\
\hline $43 D A T$ & Testemunha & 44,000 & A & & Guarda-chuva & 169,02 & A & \\
\hline $17 / 04 / 97$ & Tela plástica & 37,083 & B & & Testemunha & 142,48 & A & \\
\hline \multirow{3}{*}{$\begin{array}{l}\text { Média geral dos } \\
\text { tratamentos }\end{array}$} & Guarda-chuva & 44,72 & & & Guarda-chuva & 204,84 & & \\
\hline & Tela plástica & 35,73 & & & Tela plástica & 168,33 & & \\
\hline & Testemunha & 38,36 & & & Testemunha & 158,39 & & \\
\hline \multirow{3}{*}{$\begin{array}{l}\text { Coeficiente de } \\
\text { variação (CV \%) }\end{array}$} & Guarda-chuva & 26,65 & & & Guarda-chuva & 49,17 & & \\
\hline & Tela plástica & 26,84 & & & Tela plástica & 49,40 & & \\
\hline & Testemunha & 28,41 & & & Testemunha & 52,84 & & \\
\hline
\end{tabular}

*Médias não seguidas pela mesma letra diferem estatisticamente entre si pelo teste de Duncan em nível de 5 \% de probabilidade de erro.

ainda que as temperaturas do ar estejam num nível elevado (1aㅡ e 3a épocas de cultivo no verão). Assim, pode-se afirmar que os ganhos de massa foliar e de número de folhas foram satisfatórios nos cultivos de verão sob os túneis $G C$, com efetiva proteção das chuvas convectivas, tendo ventilação razoável com as aberturas de $0,10 \mathrm{~m}$ nas laterais dos túneis e equivalente ao tratamento com túneis Tela.

\section{CONCLUSÕES}

Recomenda-se a utilização de túneis plásticos tipo guarda-chuva na cobertura dos cultivos de alface em todas as épocas do ano, sendo necessário o ajuste das suas aberturas laterais com no mínimo 0,10m de altura no período de verão e $0,05 \mathrm{~m}$ no período de inverno.

A utilização de filmes plásticos perfurados na cobertura de cultivos de alface é viável no período de inverno e a tela plástica é indicada para a época mais quente do ano, em torno do solstício de verão.

\section{AGRADECIMENTOS}

Os autores agradecem ao Conselho Nacional de Desenvolvimento Científico e Tecnológico (CNPq) e à Fundação de Amparo a Pesquisa do Estado do Rio Grande do Sul (FAPERGS), pelas bolsas concedidas e pelo financiamento da pesquisa.

\section{REFERENNCIAS}

BURIOL, G.A. et al. Efeito da ventilação sobre a temperatura e umidade do ar em túneis baixos de polietileno transparente e o crescimento da alface. Revista Brasileira de Agrometeorologia, Santa Maria, v.5, n.1, p.17-24, 1997.

BURIOL, G.A. et al. Alterações micrometeorológicas causadas por túneis baixos de tela plástica preta cultivados com alface. Ciência Rural, Santa Maria, v.24, n.1, p.1-6, 1994.

BURIOL, G.A. et al. Modificação ambiental causada por túneis baixos de polietileno transparente perfurado cultivados com alface. Ciência Rural, Santa Maria, v.23, n.3, p.261-266, 1993.

CERMEÑO, Z.S. Prontuário do horticultor: mais de 10.000 dados úteis. Lisboa: Litexa, 1988. 408p.

Ciência Rural, v.37, n.3, mai-jun, 2007. 
EMBRAPA. Sistema brasileiro de classificação de solos. Brasília: Embrapa Produção de Informações; Rio de Janeiro, Embrapa solos, 1999. 412p.

FILGUEIRA, F.A.R. Novo manual de olericultura: agrotecnologia moderna na produção e comercialização de hortaliças. Viçosa: UFV, 2000. 402p.

GIMENES, E.S. et al. Efeito da atenuação da densidade de fluxo da radiação solar incidente no crescimento da alface. Ciência Rural, Santa Maria, v.24, n.2, p.241-246, 1994.
LUFT, S.V.L. Efeito do manejo de túneis baixos de polietileno transparente sobre o microambiente. 1994. 84f. Dissertação (Mestrado em Agronomia) - Curso de Pósgraduação em Agronomia, Universidade Federal de Santa Maria, Santa Maria.

ROBLEDO, F. de P.; MARTIN, L.V. Aplicacion de los plasticos en la agricultura. Madrid: Mundial-Prensa, 1981. 553p.

STRECK, N.A. et al. Crescimento da alface em túneis baixos com filme de polietileno perfurado. Ciência Rural, Santa Maria, v.24, n.2, p.235-240, 1994. 